\title{
BEING CHINESE IN AOTEAROA NEW ZEALAND: THE IMPORTANCE OF CONFUCIANISM AND TAOISM IN THE LIVES AND SELVES OF NEW IMMIGRANTS
}

Minghong Sun, Sue Cornforth and Lise Bird Claiborne

\begin{abstract}
We present a short commentary on the ongoing relevance of Confucianism and Taoism for recent Chinese migrants and, subsequently, for those who work with them. It is based on a thesis by one of the authors, Minghong Sun (2007), who explored what it means to identify as Chinese within a Euro-western setting, particularly in relation to coping strategies and the counselling interventions that might be offered. Her study investigated how recent migrants, with a strong enculturation as Chinese selves in their early lives, responded to their host country's socio-cultural environment, focusing on migrants from mainland China in New Zealand. The study emphasised the continuing importance of the influence of Confucianism and Taoism in the lives of Chinese immigrants. The findings of the study have relevance not only for counselling, but also for educators and those who provide work-based interventions such as mentoring, coaching and professional development for Chinese migrants.
\end{abstract}

\section{INTRODUCTION}

New Zealand's cultural landscape has been altered by the expanding immigration from mainland China in recent decades. 'Asians' are the fastest growing ethnic group in New Zealand by far, being 9.2 percent of the population in the 2006 census (Statistics New Zealand 2007). Tertiary education students have been the latest wave of Chinese peoples coming to this country, and many have remained to make their homes here. It has been estimated that in the next fifteen years the proportion of the student population of European ethnicity will decrease, while the proportion of students from various other ethnic groups will increase, with an expected increase in Asian students from 12 to 16 percent (McClelland 2006). This population shift poses challenges for the cultural sensitivity of the country's social services. 
Comparatively little has been written on the difficulties Chinese immigrants may have had in studying and/or settling in New Zealand, although there is a growing body of relevant knowledge (e.g. Abbot, Wong, Giles, Wong, Young and $\mathrm{Au}$ 2003; Abbot, Wong, Williams, Au, and Young 1999; Eyou, Adair and Dixon 2000; Rasanathan, Ameratunga and Tse 2006). One of the authors explored this question to consider the appropriateness of counselling services for immigrants that typically offered only traditional Euro-western counselling interventions (Sun 2007). The focus was on young people from mainland China whose sense of self is strongly linked with longstanding Chinese traditions of Confucianism and Taoism. ${ }^{1}$ The research was an exploration of religious and secular texts that also included informal discussions with local Chinese students and longer-term immigrants. The thesis concluded with recommendations for counsellors working with recent Chinese immigrants. This article gives a brief overview of this research, focusing on the ways that Confucian and Taoist understandings frame many contemporary Chinese people's views of themselves, and are extremely important for their ways of coping with society in Aotearoa. We conclude with implications for the provision of social services to Chinese immigrants in Euro-western countries.

In the field of counselling, provision of services to clients from cultures other than Euro-western ones is still a contested field. Counsellors working with minority ethnic clients have described themselves as 'working in the dark' and as being only able to 'guess what the best ways to help are' (Neilson and Liddle 1997:16, cited in Chu 2002). Simultaneously several studies have found that ethnic minorities, including Asian peoples, are less likely than people of the dominant culture to take advantage of public counselling services (Atkinson and Gim 1989; Vong 2002). These studies illustrate that cultural values were obstacles preventing ethnic minorities seeking help from professional counsellors. While some in the USA (e.g. Atkinson and Gim 1989; Vong 2002) have argued that people from minority ethnic groups are less likely to seek counselling than those from the dominant culture, Ying and $\mathrm{Hu}$ (1994) found that Asian Americans had a high rate of service use, but experienced less effective treatment and poorer outcomes. They argued that the main barriers for Asian people seeking help from counselling may not be from their cultural values but may be from inappropriate counselling services.

The field of counselling has in recent decades been greatly concerned with questions of culture (McLeod 2003), embracing an ethical imperative to be 'culturally aware and sensitive in [their] counselling work' (Moir-Bussy and Sullivan 2006:163). These concerns have emerged in tandem with indigenous peoples' claims for justice, particularly since the 1980s. The New Zealand As- 
sociation of Counsellors' (NZAC) code of ethics directs members to be aware of cultural diversity and to offer appropriate services to clients, to ' $[a] \mathrm{ct}$ with care and respect for individual and cultural differences and the diversity of human experience' (NZAC, 2002, section 4.1). Research findings (e.g. Rasanathan et al. 2006) support this ethical imperative, identifying a 'policy void' where Asian health is concerned.

Of course, defining the requirements of a culture in order to be sensitive can lead to stereotyping of culture as static (Chantler 2005). Further, Eleftheriadou (1992:501) argued that generalist approaches to cultural counselling based on some 'inherent universal aspect across cultures' would be unlikely to take into account the real socio-political issues facing an individual from an ethnic minority group. She expressed her suspicion of exercises aiming at 'distilling' culture or creating a 'compilation of cultures', arguing that such exercises create an 'essentialised and rigid view of culture' more likely to reflect the interests of the dominant groups (Eleftheriadou 1992: 242). There is the further danger that the source of an individual's difficulties (e.g., depression or job insecurity) might be ascribed to a person's culture or ethnicity, rather than to a wider structural problem such as racism (Atkinson, Thompson and Grant 1993). Chantler (2005: 244) argued that focusing only on culture itself in using such phrases as 'working with difference/diversity' and 'being culturally sensitive' would only function as 'glossing over institutional and systemic power relations' leading to the events such as racial harassment and violence that many minoritised people experience. She suggested that a glib use of these phrases provides a 'comfort zone' that allows dominant groups to deny the socio-political realities of minority groups. She questioned current counselling strategies that decontextualise differences 'at a surface level' (Chantler 2005: 241).

In this paper we look beyond the concept of cultural difference, to consider the influence of philosophical belief in coping with life's challenges. What helpful positions do the philosophies of Confucianism and Taoism make available to Chinese people? We take this line of inquiry both in response to a growing interest in philosophy in therapy (e.g. Bond 2000; Combs 1986; Combs and Soper 1963; Eaton 2002; McLeod and McLeod 1993), and in response to the resurgence of interest in Confucian and Taoist works within China.

INTRODUCING CONFUCIANISM AND TAOISM

Confucianism and Taoism are widely considered as the two most influential sources of the Chinese self. Common to both these systems is the ancient Chinese vision of the cosmos as 'a spontaneously self-generating life process' (Tu 
1985a: 8) based on the motifs of 'continuity', 'wholeness' and 'dynamism' (Tu 1984). Such a worldview plays down dichotomies such as self/society, body/ mind and nature/nurture. Additionally, the individual self is seen as having an inexhaustible potential for development just as the cosmos does.

The Confucian perspective emphasises a focus on the self as active and transcendent, founded on the two key notions of human relations (ren lun) and humanity (ren). In Confucianism the ultimate goal is how to know the self and become a humane person. This means, first, that the self is situated in human relations rather than being a lonely entity isolated from its surroundings (Wang 2002). In order to know oneself, the individual needs to participate actively in various human relationships as the means rather than the end to knowing the self and ultimately to embarking upon the path to humanity (Tu 1985a, 1985b). Only through participation in the ordinary daily human relatedness of family, community and state can the self gain the opportunities to discover the innate virtues and to practise them and to transcend him/herself to be a humane person (Wang 2002). Secondly, individuals need to discover and restore their authentic self and ultimately to become a humane person in their interactions with others (Fung 1953). These ideas are brought together in the expression, 'what the superior man seeks, is in himself. What the mean man seeks, is in others' (Analects XV in Legge 1877:226). Here the self is clearly a more collective self than is usual in western understandings (see Johnson 1985).

Equally important for understanding the philosophical underpinnings of a Chinese self is the influence of Taoism. There are two key terms in this philosophy, namely Tao and shengren, which play a significant role in understanding the self as balanced and powerful in Taoist philosophy. Though the term Tao is perhaps the most important concept in Chinese philosophy (Zhang 2002), and can also be found in Confucianism, Taoist sources are the most important for understanding this philosophy.

Laozi is considered to be the writer of the central Taoist text, Tao Te Ching. For Laozi, Tao or 'the Way' is more fundamental than heaven and is the absolute beginning, the origin of wanwu (all things). Wanwu carry the yin and the yang and associated harmony. In Taoism, shengren (the sage) is the idealised person. The wise people possess Ming (a holistic wisdom beyond the conventional knowledge) which makes it possible for them to recognise what Tao is and follow the virtues of Tao. The wise avoid exerting external influences, and instead allow all to realise their inner potential power, their ziran (self-becoming) (Roberts 2001). As long as all things resonate with their ziran, the original 
power endowed by Tao will be manifested. Therefore, $\mathrm{Te}$ (virtue) can be understood as power and Tao Te Ching can be translated as Tao and its power.

Within Taoism the self, like everything in the universe, is a reconciler of the opposites-yin and yang-and the self-seeking harmony between yin and yang is also the foundation of its development (Coward 1996; Fowler 2005). As long as the self is in equilibrium, in the balanced state of yin and yang, the person is in tune with Tao and will get $\mathrm{Te}$ (power). Once the self discerns the principle of wanwu (harmony of yin and yang), the self will become powerful since the way is 'nothing more than power that lies within things, and the power is itself the manifestation of the way' (Miller 2003:50).

For Taoists to cultivate themselves in accordance with Tao as wise persons is the ultimate goal. This does not refer to acquiring conventional knowledge, since 'the Tao [that] can be told of is not the absolute Tao' (Tao Te Ching 1 in Lin 1948: 27). The Taoist self appears to be nihilistic who chides and admonishes the zealots pursuing knowledge, talents and morals. In Tao Te Ching and Zhuangzi's Zhuangzi, words or similar words such as $w u$ (nothing/non-being), $w u$ wei (non action or non-doing) repeatedly appear. For example, in Tao Te Ching 11, 'thirty spokes unite around the nave, from their not-being arises the utility of the wheel. Mould clay into a vessel, from its not-being arises the utility of the vessel. Cut out doors and windows in the house, from their not-being arises the utility of the house' (Lin 1948:32). Therefore, just as we take advantage of what is, we should recognise the usefulness of what is not.

Confucianism and Taoism, as two indigenous sources of Chinese tradition and culture, undoubtedly exert great influence on what defines the Chinese self. On the surface, two schools of philosophy seem to be in opposition and often come into conflict in Chinese history (Morris 1994). However, Confucianism and Taoism share common theoretical heritage such as Tao, yin and yang. Some writers suggest that these two schools of philosophy can be viewed as yin and yang polarities within Chinese cultures: 'the one (Taoism) idealistic, the other realistic (Confucianism), but together the perfect combination offsetting and connecting each other and preventing too unconstrained on the one side or too rigid a classicism on the other' (Cooper 1990:3). It is the interplay of Confucianism and Taoism that makes the Chinese self. A folk saying that aptly describes the functions of Confucianism and Taoism as yang and yin respectively (Allinson 1989:15) is 'every Chinese person is both a Confucian and a Taoist; he is a Confucian when everything is going well; he is a Taoist when things are falling apart.' 
COPING DIFFERENTLY

Scholars working with Chinese communities have argued that Chinese could take advantage of the above philosophies in coping with psychological distress (e.g., Ying and Hu 1994; Yip 2005; Yue 2001). This was certainly Sun's (2007) conclusion. Drawing on her earlier work, in the following section we consider how these themes might be played out in three imaginary scenarios. As the above writers suggest, our imaginary actors draw on a range of strategies. Two have considered, and find lacking, typical Euro-western interventions (see also Tata and Leong 1994). All draw meaning from a combination of Confucian and Taoist philosophies. We construct these scenarios around various case studies, anecdotes and common migration-related problems, such as unemployment, study stress, racial discrimination and relationships with local persons, to explore how new Chinese migrants in Aotearoa might relieve stress through culturally constructed coping strategies.

\section{THE CASE OF MIN: DIFFICULTIES FINDING WORK}

The first example is drawn from a previously published study (Lam and Palsane 1997). Min was a male Chinese immigrant who suffered from depression. He frequently complained that he was useless, as he had been unemployed for a couple of years. Previously, he had been a senior professional mechanical engineer in mainland China. However, the jobs available to him (in the host country) were in manual labour, cleaning or waiting in Chinese restaurants. He refused to accept his present situation and was angry about his wife's decision to immigrate to New Zealand. He felt fatigued and had no interest in participating in any activities. A social worker approached him and empathised with his situation. However, the more the worker listened to his story, the stronger Min's negative feelings became. Finally, as Min tried to recall his knowledge about the doctrines of Taoism and Confucianism, his depressed mood was relieved.

Min said that he felt that memories of past honour and status were creating a barrier in his search for inner peace and the needs of his true self. Through self-reflection he told himself that he was indeed 'useless' in comparison with the old $w o$-self ${ }^{2}$ that he was eager to abandon. That wo-self had confined him in complicated 'guanxi' (relationships) in his work and social environment limiting his time with his wife and son. On the other hand, after immigration, he had more time with the family and became closer to his son who looked happier. That was the need of his real self and this understanding helped him turn away from past secular things such as honour and status. 
Additionally, Min reminded himself about the ideas of Laozi, 'returning is the movement of the way' (Tao Te Ching 40 in Legge 1962). 'All things alike go through their processes of activity, and we see them return (to their original state)... this returning to their root is what we call the state of stillness' (Tao Te Ching 16 in Legge 1962:59). Consequently, he began to accept and regard his current situation as 'returning to the state of stillness', Tao, which is the root of one's authentic happiness and the way by which to nourish one's life. Finally, through recalling his knowledge and understanding of Chinese traditional culture, he explored new and different perspectives on life and happiness, and thus ceased fixating on the honour and status that he had held in China.

THE CASE OF YING: DIFFICULTIES WITH A LONG DISTANCE RELATIONSHIP

This next case study is based on informal interviews conducted for the research project. Ying was dissatisfied with her job in her host country. She decided to return to university and obtain the local certification that she believed would help her find better employment. Her husband, who was finding it very difficult to find a suitable position, returned to China. He knew that Ying's study would take a couple of years and that his financial support was needed. They chose 'astronaut migration, ${ }^{3}$ and Ying and her husband began their 'single' lives in the host country and in China respectively. However, after a period of single life, Ying realised that maintaining the quality of their relationship was not as easy as she had imagined. Additionally, being a mature student and studying with those who were much younger sometimes made her lose selfconfidence and become irritable.

Ying relieved her stress in the following ways. First, she reminded herself that happiness was not accidental, but was rather the outcome of her own effort. Therefore she strove to be self-reliant in taking responsibility for finding her and her family's happiness. In order to restore the quality of her relationship with her husband, she increased not only the amount of time, but also the ways in which to communicate with him each week. Additionally, she decided to establish a close social relationship to which she could commit herself and contribute her abilities and passions. She joined a local Chinese church community in which she already had some contacts, and made some good friends who made her migration experience valuable and worthwhile (see also Wong and Everts 2002).

Secondly, Ying told herself that she should 'take it easy', since it is nature that 'a violent wind does not last a whole morning, and a sudden rain does not last for the whole day' (Laozi 23 in Legge 1877). So she considered her present 
'adverse' situation to be temporary but would ultimately pass. She believed that it was more important to concentrate on her studies and be tolerant and patient, consistent with the old Chinese saying, 'a hundred forbearances become golden' (Lam and Palsane 1997:277). She believed that both herself and her marriage would become stronger and happier after suffering this period of distance from her husband.

\section{THE CASE OF FEI: COPING WITH PAKEHA FLATMATES}

Fei was a 25-year-old Chinese graduate working in a government department in New Zealand. He chose to share a flat (shared accommodation) with two New Zealand co-workers, rather than find lodgings, because he believed that, as an adult, he was experienced and able to take care of himself and get along with the locals. However, it was not long before he realised that there were things that upset him and affected his feelings and his relationships with his flatmates. The habits of his local flatmates were very different from his own. For example, they always left their dishes in the sink after a meal. As a result, if he cooked after them, he could not find clean dishes and had to wash their dirty dishes before he could use them. In his experience, Chinese flatmates would acknowledge what he had done for them and return the favour. However, his current flatmates made no such response and left the dishes in the sink as usual. He talked about this issue with a local friend. His friend suggested that he should tell his flatmates about his problem and ask them to clean their dishes after they had cooked.

Fei did not accept his friend's suggestion and chose not to confront his flatmates about their habits. Instead he took the view that changes would happen naturally and smoothly over time, and took the action of 'let-it-happen' (Yip 2005; Yue 2001). He felt awkward about confronting them since he thought that most of the time his flatmates were kind and helpful to him. So, as an individual knowing 'renqing' (human feeling) (Barnes 1998: 415), he decided that helping the flatmates with their dishes could be a way of responding to their kindness and help. He told himself that his flatmates were young and had no experience living with others, especially foreigners, reminding him of the first time he left home and lived in a dormitory with classmates. He believed that as time went on his flatmates might change, just as he had, and know 'the feelings of others without needing to be told,' to become a person of knowing 'renqing' (Barnes 1998: 415).

The other reason Fei did not accept his friend's suggestion is that he believed that maintaining ' $h e$ ' (harmony) with his flatmates was of utmost importance 
(Yue 2001), since they were living under the same roof and saw each other every day. If the ' $h e$ ' were broken by any confrontation, he imagined that both parties might feel awkward, uncomfortable and unhappy in their living environment. Therefore, in order to live happily and comfortably it was worth enduring his flatmates' unintentionally inconsiderate behaviours for the sake of keeping ' $h e$ ' with them.

\section{DISCUSSION}

From the above, it will be seen that the interplay of Confucianism and Taoism offers five important philosophical positions from which to approach the problems associated with migration and acculturation: acceptance of being in a 'half-and-half' situation; belief in everlasting change as the pattern of nature; being good at self-reflection and self-control; being content with simple life; and being self-reliant in pursuing one's own ultimate and imperishable happiness. These are somewhat removed from the traditional tenets of Euro-western psychology and yet, they have the potential to provide viable, alternative solutions for many Chinese.

First, immersed in the opposite influences of Confucianism and Taoism, many Chinese have thoughts that are half Taoist and half Confucian and tend to seek a perfect balance between these opposite discourses (Lin 1938). According to Lin, these half-and-half Chinese thoughts can be regarded as the 'balm' that provides self-protection and 'soothes the wounded Chinese soul' (Lin 1938:117). On the one hand, the discourses of Confucianism have encouraged Chinese to be active and rational, to be successful in society, and to bring about honour to themselves and their families. However, the discourses of Taoism have trained Chinese selves not to be too anxious about reality and the secular world, and not to impose too many restraints and limits on their lives. Consequently, such a half-and-half situation may offer Chinese migrants more opportunities to prevent distress arising from either extreme. This doctrine of half-and-half is attributed to Confucius's grandson, Zisi, and is eloquently expressed in Li Mian's 'half-and-half song' (cited Lin 1938: 122-123).

\section{By far the greatest half I have seen through}

This floating life-ah, there is a magic word-

This 'half'-so rich in implications.

It bids us taste the joy of more than we can ever own.

Half-way in life is man's best state, when slackened pace allows him ease; A wide world lies half-way twixt heaven and earth;

To live half-way between the town and land, 
Have farms half-way between the streams and hills;

Be half-a-scholar, and half-a-squire, and half in business;

Half as gentry live, and half related to the common folk...

Half thinking how for my posterity

To plan and provide, and yet half minding how

To answer God when the body's laid at rest...

Who half too much has, adds anxiety,

But half too little, adds possession's zest.

Since life's of sweet and bitter compounded,

Who tastes but half is wise and cleverest.

Secondly, both Confucianism and Taoism imply that everlasting change is the inevitable pattern of nature. Both philosophies continually remind Chinese selves to be tolerant of uncertainty and to be patient in waiting for better times (Blofield 1978; Yip 2005). For Confucius, '[everything] passes on just like [the stream], not ceasing day or night' (Analects IX in Legge 1877:171). Furthermore, Confucius was confident in the trend of development and improvement in the future and the individual (Yan, Yang and Zhu 1988). He said, 'a youth is to be regarded with respect. How do we know that his future will not be equal to our present?' (Analects IX in Legge 1877:172).

Whereas Confucian beliefs see change directed towards a good future, the movement of everything in the universe, for Tao, is 'reversion' (Tao Te Ching 40 in Lin 1948: 48). Therefore, 'something and nothing,' 'the difficult and the easy', 'the long and the short', 'the high and the low', 'note and sound' and 'before and after' are destined to be relatively existent and to complement and follow each other (Tao Te Ching 2 in Legge 1962: 48). For the same reason, the reference above to the temporality of 'a violent wind' or 'sudden rain' asks us to be patient in waiting for more positive change (Tao Te Ching 23 in Legge 1962: 67). Moreover, the 'returning' movement of Tao has determined the benefit of weakness, and the usefulness of nothing or not-being, since the presence of something such as a 'vessel' or a 'house' is born from nothing or not-being. Just as we take advantage of what is, we should recognise the usefulness of what is not.

Thirdly, both Confucianism and Taoism advocate knowing and being one's true self, making Chinese selves well-versed in self-reflection, self-control, and selfevaluation (Cheung 1986; Mok 2001; Yue 2001). To learn to be one's true self, it is necessary for the individual to have 'a wide and extensive knowledge of what has been said and done in the world; critically to inquire into it; carefully to ponder over it; clearly to sift it; and earnestly to carry it out' (Lin, 1958: 110). 
Living among people, learning good from others and practising what they have learned, while not losing oneself, requires a strong sense of autonomy and self-reflection. Thus, Chung-ying Chen argued that the self in Confucianism has the 'ever reflective self-conscious capacity of relational thinking, which articulates itself in logical and moral reasoning and develops itself in terms of its interaction with the world, culture, history, learning and knowledge' (cited in Jiang 2006:544). So, Confucianism's self-cultivation requires individuals to relate with others and meanwhile requires individual autonomy, entailing a self-reflective understanding of the self (Jiang 2006).

In Taoism, ' $[h]$ e who knows others is learned. He who knows himself is wise. He who conquers others has power of muscles. He who conquers himself is strong' (Tao Te Ching 33 in Lin 1948:44). In comparison with Confucianism, a Taoist's means of expressing the true self is not learned from the 'truth' of man. Rather, 'strength' is needed to overcome the conventional 'truth' of man in order to discover and restore the authentic self. 'He who is contented is rich. He who is determined has strength of will. He who does not lose his centre endures. He who dies yet (his power) remains has long life' (Tao Te Ching 33 in Lin 1948:44). In other words, individuals should know 'their station' and limitations on the basis of rational and wise self-evaluation and self-reflection. Knowing their limitations, the Taoist should be content with what they have possessed, and find and persevere with what they need to do. In this way they access the power of Tao, which can endure eternally, even after death (since Laozi believed in existence of another life for an individual after its present life; see Legge 1962).

Fourthly, both the Chinese schools of philosophy encourage people to enjoy and be content with a simple life. This helps Chinese to be emancipated from disappointment due to extravagant demands for secular perceptions (Lin 1938). In Confucianism, 'the life of the moral man is plain, and yet not unattractive; it is simple, and yet full of grace; it is easy, and yet methodical' (Zisi, Tr. Ku Hongming in Lin 1958:118). Even living in extreme poverty, 'the superior man may indeed have to endure want' to contrast with 'the mean man' who 'gives way to unbridled license when he is in want' (Analects XV in Legge 1877:223). These doctrines imply that the reason a moral man can endure poverty and enjoy a simple and plain living style is that he can find life's meaning and value through self-cultivation. If people cannot live happily in poverty, how can they accomplish the great things and 'enter into the world of ideas and morals?' (Analects XV in Legge 1877:223). 
In comparison, Taoists view secular perceptions such as wealth, attainment, honour and pride as very dangerous and liable to invite trouble:

Stretch a bow to the very full, and you will wish you had stopped in time. Temper a sword-edge to its sharpest, and the edge will not last long. When gold and jade fill your hall, you will not be able to keep them safe. To be proud with wealth and honor is to sow the seeds of one's own downfall (Laozi 9 in Lin 1948:31).

Furthermore, the danger in the pursuit of the secular also derives from the fact that 'human life is limited' but secular perceptions are 'limitless'. As a result, it is impossible, and even fatal, to 'drive the limited in pursuit of the limitless' (Zhuangzi in Lin 1948, 84). An unwillingness to live simply and plainly, indulging in extravagant lives, will deplete one's capacity to discover and restore one's true mind and the freedom of self and being. This is because 'five colours blind the eyes of man; the five musical notes deafen the ears of man; the five flavours dull the tastes of man; horse-racing, hunting and chasing madden the minds of man; rare, valuable goods keep their owners awake at night' (Tao Te Ching 12 in Lin 1948:32). One must live simply and plainly, transcending secularity, in order to find one's true self and freedom of being.

Finally, both Confucianism and Taoism tell people to be self reliant in pursuing ultimate and imperishable happiness. In Confucianism, ultimate happiness is achieved once individuals have realised their true selves, reached their greatest height equal with heaven and earth, and live in accordance with nature. Self-cultivation is the only way for individuals to reach this stage. As Mencius put it, 'the principle of self-cultivation consists of nothing but trying to look for the lost heart' (cited in Lin 1958: 235). The lost heart is in the true self who knows the life and the way of happiness. However, this self-cultivation cannot be without connectedness with others through which they can learn and practise 'central harmony'. According to Zisi (the grandson of Confucius), the harmony is 'when the passions such as joy, anger, grief, and pleasure awaken and each and all attain due measure and degree', and 'harmony or moral order is the universal law (Tao) in the world' (Doctrine of the Mean I: Gu Hongming in Lin 1958:96). To attain ultimate happiness, individuals should live their life like the moral man who unceasingly cultivates himself to learn and practice the moral law.

According to Taoism, individuals who have achieved absolute happiness are those who 'attain the utmost in Humility and hold firm to the bias of Quietude' (Tao Te Ching 16 in Lin 1958:34). They are like 'water' demonstrating three 
characters: benefiting ten thousand creatures, being soft and not competing with ten thousand things, and dwelling in abject places that all disdain (Tao Te Ching 8 in Lin 1958). It is necessary to understand the spirit of being useless and the power of being non-active. Even if regarded as useless by others, the individual should enjoy the happiness of being of no use and not strive to become useful according to others' standards. All the above characteristics are the virtues of Tao in human beings and reality (Chen 1998).

\section{FINAL THOUGHTS AND IMPLICATIONS}

The philosophies of Confucianism and Taoism offer very different positions to those who have been immersed in their influence since birth. In an increasingly globalised world it is important to acknowledge that there are many ways of dealing with life's various stresses and crises. In particular, there are alternatives to the interventions more usually offered by the various Euro-western psychologically oriented professions. We think that these philosophies offer insights that may be useful, not just to counsellors, but also to others who work with new migrants. It would seem to us that an understanding of the above five life positions might be better utilised in various workplaces which employ, train or teach new Chinese migrants including those who are recent graduates. It is obvious that these five themes are played out in the life worlds of new migrants: they are between worlds; experiencing and expected to deal with change; continually reflecting on different cultural responses; often financially insecure; and often thrown back on their own resources, having left family and possessions behind. Confucianism and Taoism provide positions from which to attend to these challenges, while imposing Euro-westernised solutions may cause further problems.

There are two implications for those who wish to be of assistance to Chinese who are recent migrants. First, if, as is suggested above, the self is situated in human relations, then it would seem particularly important to ensure that new Chinese migrants are embedded in networks of human relationships within their organisation or social setting. As part of this, the importance of ordinary and everyday social contact and inclusion cannot be under-estimated. Secondly, as Day-Vines, Wood, Grothaus, Craigen, Holman, Dotson-Blake and Douglass (2007) note, an emerging body of research supports the importance of raising and inquiring about cultural factors in cross-cultural relationships that are experienced as helpful. To this end, we think it important to foreground the possible relevance of Confucianism and Taoism and make some of its principal tenets available for discussion. 
As we write this paper, the Olympic torch is being carried throughout the world on its way to Beijing. It has become pivotal in centralising a range of diverse and passionate concerns directed at China's relationships with the rest of the world. It also symbolises the possibility of on-going dialogue, debate and discussion. Therefore, within a global context of increasing contact with Chinese people that we offer Minghong Sun's work, so that we may learn from Tao not to impose solutions 'according to others' standards', and that we might engage in the Confucian aspiration of working towards greater 'knowledge, benevolence and harmony.'

\section{NOTES}

1 We realise that it would be difficult to discuss the influence of Chinese traditional teachings without mentioning Buddhism, which is extremely important in everyday life for people in China and for Chinese immigrants to New Zealand. We also acknowledge that there are complex relationships between Buddhism, Confucianism and Taoism. This paper is based on the first author's work that focused only on the latter two systems of thought, since further expansion was beyond the scope of a Master's thesis.

2 In Chinese, both $w u$ and wo refer to 'I' or self. $W u$-self is sometimes referred to as the authentic self, filled with self-awareness about things, the world and the universe. The wo-self, in Zhuangzi's Zhuangzi, is said to cut one off from the natural principle of the myriad things, or puts one out of accord with the Tao. This creates the saying, 'wu sang wo' (I lose myself).

3 Astronaut migration refers to migrants who spend lengthy periods out of New Zealand after taking up residence. They are typically believed to return to their country of origin to work or do business while leaving their spouse and children in New Zealand.

\section{REFERENCES}

Abbot, M.W., S. Wong, L.C., Giles, W. Young and M. Au 2003 'Depression in Older Chinese Migrants to Auckland, Australian and New Zealand Journal of Psychiatry, 37 (4): 445-451.

Abbot, M.W., S. Wong, M. Williams, M. Au, M. and W. Young 1999 'Chinese Migrants' Mental Health and Adjustment to Life in New Zealand', Australian and New Zealand Journal of Psychiatry, 33 (1):13-21. 
Allinson, R.E. 1989 'An Overview of the Chinese Mind', in R.E. Allinson (ed.) Understanding the Chinese Mind: The Philosophical Roots, Oxford: Oxford University Press: $1-25$.

Atkinson, D.R. and R. H. Gim 1989 'Asian-American Cultural Identity and Attitudes Towards Mental Health Services', Journal of Counseling Psychology, 36:209-212.

Atkinson, D.R., Thompson, C.E. and S. K. Grant 1993 'A Three-dimensional Model for Counseling Racial/Ethnic Minorities', The Counseling Psychologist, 21 (2):257-277.

Barnes, L.L. 1998 'The Psychologizing of Chinese Healing Practices', Culture, Medicine and Psychiatry, 22: 413-443.

Blofield, J. 1978 Taoism: The Road to Immortality, Boulder: Shambhala Publications.

Bond, T. 2000 Standards and Ethics for Counselling in Action, London: Sage.

Chantler, K. 2005 'From Disconnection to Connection: "Race", Gender and the Politics of Therapy', British Journal of Guidance and Counselling, 33 (2):239256.

Chen, G.Y. 1998 Laozi Zhuyi ji Pingjia, Hong Kong: Zhonghua Shuju (Hong Kong).

Cheung, F.M.C. 1986 'Psychopathology among Chinese people', in M.H. Bond (ed.) The Psychology of the Chinese People, Oxford: Oxford University Press: 171-212.

Chu, S. 2002 'An Overview of the Geographical Backgrounds of the New Waves of Chinese Immigrants to New Zealand', New Zealand Journal of Counselling, 23(1):15-20.

Combs, A.W. 1986 'What Makes a Good Helper? A Person-Centred Approach', Person Centred Review, 1:51-61.

Combs, A.W. and D.W. Soper 1963 'The Perceptual Organisation of Effective Counsellors', Journal of Counseling Psychology, 10: 222-227. 
Cooper, J.C. 1990 Taoism: The Way of the Mystic, Wellingborough: Crucible.

Coward, H. 1996. 'Taoism and Jung: Synchronicity and the Self', Philosophy East and West, 46 (4): 477-496.

Day-Vines, N., S. Wood, T. Grothaus, L. Craigen, A. Holman, K. Dotson-Blake and M. Douglass 2007 'Broaching the Subjects of Race, Ethnicity, and Culture During the Counseling Process', Journal of Counseling and Development, $85(4): 401-410$.

Eaton, J. 2002 'Psychotherapy and Moral Inquiry', Theory and Psychology, $12(3): 367-386$.

Eleftheriadou, Z. 1992 'Cross-cultural Counseling Psychology', in R. Woolfe, W. Dryden and S. Strawbridge (eds) Handbook of Counselling Psychology, London: Sage Publications: 500-517.

Eyou, M.L., V. Adair and R. Dixon, 2000 'Cultural Identity and Psychological Adjustment of Adolescent Chinese Immigrants in New Zealand', Journal of Adolescence, 23 (5): 531-543.

Fung, Y.L. 1953 A History of Chinese Philosophy, Princeton: Princeton University Press.

Fowler, J. 2005 An Introduction to the Philosophy and Religion of Taoism: Pathways to Immorality, Brighton, Portland: Sussex Academic Press.

Ho, E., S. Au, C. Bedford and J. Cooper, 2002 Mental Health Issues for Asians in New Zealand: A Literature Review, Wellington: The Mental Health Commission.

Jiang, X.Y. 2006 'The Concept of the Relational Self and its Implications for Education', Journal of Chinese Philosophy, 33 (4):543-555.

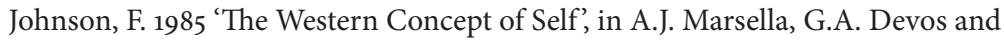
F.L.K. Hsu (eds) Culture and Self: Asian and Western Perspectives, New York: Tavistock Publications: 91-138.

Lam, D.J. and M.J Palsane 1997 'Research on Stress and Coping: Contemporary Asian Approaches', in H.S.R. Kao and D. Shinha (eds) Asian Perspectives on Psychology, London: Sage: 265-281. 
Legge, J. 1962 The Sacred Books of China: The Texts of Taoism, New York: DoverPublications, Inc.

Legge, J. (ed.) 1877 The Life and Teachings of Confucius, $5^{\text {th }}$ edn, London: Trubner.

Lin, Y.T. 1938 The Importance of Living, London: William Heinemann.

— (ed.) 1948 The Wisdom of China, London: Michael Joseph.

1958 The Wisdom of Confucius, London: Michael Joseph.

McClelland, J. 2006 A Changing Population and the New Zealand Tertiary Education Sector, New Zealand: Ministry of Education.

McLeod, J. 2003 An Introduction to Counselling, Buckingham: Open University Press.

McLeod, J., and J. McLeod 1993 'The Relationship Between Personal Philosophy and Effectiveness in Counsellors', Counselling Psychology Quarterly, 6(2): 121-129.

Miller, J. 2003 Daoism: A Short Introduction, Oxford: Oneworld.

Moir-Bussy, A. and B. Sullivan 2006 'Culture and Diversity in Counselling', in N. Pelling, R. Bowers and P. Armstrong (eds) The Practice of Counselling, Victoria: Thomson Learning Australia: 159-182

Mok, E. 2001 'Empowerment of Cancer Patients: From a Chinese Perspective', Nursing Ethics, 8 (1): 69-76.

Morris, B. 1994 Anthropology of the Self: The Individual in Cultural Perspective, London, Boulder: Pluto Press.

New Zealand Association of Counsellors 2002 Handbook, Hamilton: New Zealand Association of Counselors.

Rasanathan, K., S. Ameratunga, and S. Tse 2006 'Asian Health in New Zealand - Progress and Challenges', The New Zealand Medical Journal, 119 (1244) http://www.nzma.org.nz/journal/119-1244/2277/ 
Roberts, M. 2001 Dao De Jing: The Book of the Way, Berkeley: University of California Press.

Statistics New Zealand, 2007 '2006 Census Data' http://www.stats.govt.nz/census/ default.htm

Sun, M. 2007 The Chinese Self: Implications of Confucianism and Taoism for Chinese (Im)migrants and Counselling, unpublished master's thesis, Victoria University of Wellington.

Tata, S.P. and F.T.L. Leong 1994 'Individualism-collectivism, Social-network Orientation, and Acculturation as Predictors of Attitudes Toward Seeking Professional Psychological Help Among Chinese Americans', Journal of Counseling Psychology, 41:28-287.

Tu, W.M. 1984 'The Continuity of Being', in L.S. Rouner (ed.) On Nature, Notre Dame: University of Notre Dame Press: 113-129.

— 1985a Confucian Thoughts: Selfhood as Creative Transformation, New York: University of New York Press.

— 1985b 'Selfhood and Otherness in Confucian Thought', in A.J. Marsella, G.A. De Vos and F.L.K. Hus (eds) Culture and Self: Asian and Western Perspectives, New York: Tavistock: 231-251.

Vong, C. 2002 'Obstacles Preventing Chinese Migrant Students: Mental Health Issues and Guidelines for Counsellors', New Zealand Journal of Counselling, $23(1): 74-79$.

Wang, Q.J. 2002 'Genealogical Self and a Confucian Way of Self-making', International Philosophical Quarterly, 42 (1): 93-112.

Wong, J. and H. Everts 2002 'How Chinese Migrant Couples Develop Resilience', New Zealand Journal of Counselling, 23 (1): 25-32.

Yan, G.C., X.H. Yang and Y.X. Zhu (eds) 1988, Zhongguo Xinlixue Shiliao Xuanbian (1), Beijing: Renmin jiaoyu chubanshe.

Ying, Y.W. and L.T. Hu 1994 'Public Outpatient Mental Health Service: Use and Outcome among Asian Americans', American Journal of Orthopsychiatry, $64(3): 448-455$. 
Yip, K.S. 2005 'Taoistic Concepts of Mental Health: Implications for Social Work Practice with Chinese Communities', Families in Society, 86 (1):35-46.

Yue, X.D. 2001 'Culturally Constructed Coping Among University Students in Beijing', Journal of Psychology in Chinese Societies, 2 (1):119-138.

Zhang, D. 2002 Key Concepts in Chinese Philosophy, New Haven, London and Beijing: Yale University Press and Foreign Languages Press. 